\title{
Towards Enacting Social Justice in Higher Education: A Case of Postdoctoral Research Fellows
}

\author{
Zvisinei Moyo
}

\begin{abstract}
The purpose of this review was to identify the challenges confronting postdoctoral research fellows who are classified neither as staff nor students and have low socio-economic status. The three central questions were: What are the common themes in the literature and research on postdoctoral research fellows? What social justice issues arise from this research and literature? How can this literature and conceptualisation inform management of postdoctoral research fellows in terms of social justice? A total of 45 publications were reviewed. The full text of the systematically identified studies was stored in a marked folder on a computer desktop and screened by examining topics and abstracts. Each of the studies was analysed to identify six themes which are discussed using the lens of social justice, followed by suggestions for further discussion in the field. The literature portrays a culture that has undermined social justice issues and concerns. The findings challenge universities to imagine new directions for future research, and to become activists and take a pro-justice stance to formulate a culture, practices and procedures that benefit the marginalised. Universities can utilise these suggestions as a guide to evaluate their efforts and programmes.
\end{abstract}

Key words: postdoctoral research fellow, university, social justice, marginalised, transform, review

Le but de ce compte-rendu était d'identifier les défis posés aux boursiers de recherches post-doctorales qui sont classifiés ni comme personnels, ni

Aвout the Authors: ZVISINEI moyo Postdoctoral Research Fellow at the University of Johannesburg, Department of Educational Leadership and Management, P O Box 524, Auckland Park, 2006, Johannesburg, South Africa. Email: zvisinei.moyo@gmail.com 
comme étudiants, et dont le statut socioéconomique est modeste. Les trois questions centrales ont été: quels sont les thèmes communs dans la littérature et la recherche sur les boursiers de recherches post-doctorales? Quels problèmes de justice sociale surgissent de cette recherche et de cette littérature? Comment cette littérature et cette conceptualisation peuventelles influer sur la gestion des boursiers de recherches post-doctorales en termes de justice sociale? Un total de 45 publications ont été passées en revue. Le texte entier des études systématiquement identifiées a été conservé dans un dossier sur un bureau d'ordinateur et a été filtré en examinant les thèmes de recherche et les abstracts. Chacune des études a été analysée pour identifier six thèmes qui sont discutés en utilisant la focale de la justice sociale, suivi par des suggestions pour approfondir la discussion dans le domaine. La littérature dresse le portrait d'une culture qui a dévalué les problèmes et les inquiétudes reliées à la justice sociale. Les résultats encouragent ainsi les universités à imaginer de nouvelles directions à adopter pour l'avenir de la recherche, à devenir militantes et à adopter un point de vue pro-justice sociale qui permettrait de formuler une culture, des pratiques et des procédures qui bénéficient aux marginalisés. Les universités peuvent utiliser ces suggestions comme guide pour évaluer leurs efforts et leurs programmes.

\section{Introduction}

While contemporary universities confront contextual changes due to increased mobility, internationally, issues relating to postdoctoral research fellowships and future career prospects are cause for concern (Akerlind, 2005; Cantwell and Lee, 20I0). It has been observed that postdoctoral research fellows (PDRFs) tend to be invisible in academia (McQuaid, Aosved, and Belanger, 20I8). Postdoctoral research fellows from diverse cultural, racial and ethnic backgrounds are among those studying aboard (Devine, 2013). Given the historical inequalities in society (North, 2006), this raises social justice issues. While universities are taking advantage of the overflow of PhD candidates and PDRFs to increase their research output and thus improve their position in world rankings (Hallinger, 20I6), whether or not they are making efforts to promote social justice has yet to be examined at the global level.

The threats to social justice raised by academic mobility include settling on projects favoured by supervisors; discrimination based on gender, race, ethnicity, economic status, religion, language, and tradition; meritocracy; marginalisation of minority groups; homogeneity that endorses exploitation and the marginalisation of dominated countries; research only positions; and a lack of benefits and a structured support system. Collaborative international research has been harnessed to gain insight into social justice and human development in a variety of contexts. An example is the recent call to socially transform society through education (Marshall, 2004). While there is a paucity of research on PDRFs in Africa, international studies have been motivated by the marginalisation of the PDRF community at a time when globalisation and international migration have increased the flow of PDRFs (Cantwell and Lee, 20I0; Melin, 2005; Zubieta, 2009). The literature shows that while mobility of academics is believed to enhance the quality of scientific research, the current academic flow is to some extent triggered by voluntary factors and worsened by forced migration. The fast pace of globalisation may reinforce dominant cultures, further exacerbating social inequalities and discrimination (Moyo and Perumal, 20I8). Cantwell and Lee (2010) observe that Asian PDRFs seek positions in North America and Western Europe where their efforts are better appreciated and remunerated. Likewise, in Africa, which generally does not offer a conducive environment for research and where reforms, funding and policy frameworks have not kept pace with global research trends (Whitworth et al., 2008), PhD holders migrate to South Africa and Europe.

Internationalisation of higher education (HE), particularly at post-doctoral level, has bestowed uneven benefits on different groups and societies (Lee, 20I3). While it subscribes to noble goals such as mutual collaboration, skills development, career prospects, and transition to independent research, it can also have negative consequences like exploitation, low levels of remuneration and a lack of benefits, as well as marginalisation of minorities. It would seem that internationalisation reflects the interests of the dominant countries where PDRFs are received. Furthermore, host institutions are using the opportunity to obtain inexpensive contingent labour for research subsidised by external grants instead of establishing long term, expensive faculty positions. This shift does not bode well for PDRFs from abroad, especially developing countries. Scholars in the UK, US, Canada, The Netherlands, Spain, Germany, Australia and Sweden have explored the challenges experienced by international and local PDRFs (e.g., Black and Stephan, 20I0; Lee, 20I3; McAlpine and Amundsen, 20I5; Muller and Kenney, 20I4). Their work has highlighted how institutions in economically sound nations are resorting to the use of PDRFs as contingent labour which has created exploitative work conditions and muted PDRFs' voices.

Given the paucity of literature on PDRFs in Africa, the review conducted for this study addressed the following questions:

I. What are the common themes in the literature and research on PRDFs?

2. What social justice issues arise from the PDRF literature? 
3. How can this literature and conceptualisation inform management of PDRFs in terms of social justice?

Forty-five publications were reviewed, consisting of 42 journal articles, two book chapters and one conference publication. A research synthesis was employed to describe and analyse the findings, identify the social justice issues confronting PDRFs and determine the implications for PDRFs in African institutions.

This review sheds new light on the challenges faced by PDRFs who are classified neither as staff nor students. It is hoped that it will inspire further research on measures to support this group of academics who have been neglected, especially in Africa, by unveiling the significant role they play on the research front. Studies have noted that PDRFs' contribution to knowledge production is constrained by the fact that their purpose and function remain undefined, a situation which is exacerbated by their invisibility, and inferior and powerless position (Akerlind, 2005: Bodin et al., 20I8; Lembani, Teddy, Molosiwa, and Hwabamungu, 20I6; McQuaid and McCutcheon, 20I8). Furthermore, the literature points to Africa's minimal contribution to the global knowledge economy (Hallinger, 20I6). The review is thus located within the global literature on social justice with the aim of transforming the underlying social structures and societal patterns that sustain and perpetuate uneven power relations (North, 2006).

The following sections present the conceptual framework that underpinned the review and the methodology employed. This is followed by a discussion on the six themes identified in the process of data analysis using the lens of social justice. The article concludes with a discussion on the implications of the findings and recommendations for theory, practice and /or policy, as well as for future research.

\section{Conceptual Framework}

Social justice was selected to frame this review as its conceptual perspectives were appropriate to examine broad social contexts in relation to how contextual changes are affecting PDRFs. Given that social justice stems from social transformation theories, it seeks social transformation of traditional organisational structures, procedures and practices (Mthethwa-Sommers, 20I4) and calls for justice for those subjected to injustice through forms of dominance. In this case, it challenges the status quo beyond university boundaries to fight social inequalities (Capper and Young, 20I4). Social justice was deemed a useful framework as its principles aim to eliminate inequality, promote inclusiveness and establish environments that are supportive of all. The four principles of social justice discussed below were utilised (Pro Bono Resource Centre, 20II, p. 4).
2.1 Equal Access to Opportunities and Rights

This principle emphasises that all people should have access to life opportunities and other services, regardless of race, gender, sexual orientation and age. Justice is enforced to enable individuals to access goods and services and claim their rights and disadvantaged people are made aware of their rights and capacitated to enforce them.

\subsection{A Fair System of Law and Due Process}

This value concerns itself with fairness and transparency of decision making in society. It is important to social justice because it provides mechanisms by means of which all members of society are able to access justice, particular those who have less power.

\subsection{Ability to Take Up Opportunities and Exercise Rights}

This principle advocates for social inclusion and seeks to address situations where a lack of resources denies people the right to choose a life they value.

2.4 Support and Protection of Vulnerable and Disadvantaged People The final principle acknowledges that there will always be people who require support and assistance, regardless of the services provided. Social and economic structures and arrangements should benefit the disadvantaged and all should have a say in decision making.

Social justice thus calls for greater attention to be paid to unjust social and cultural processes that determine individuals' status and as well as unfair distribution of resources, in this case the low socio-economic status of PDRFs. According to Fraser (2007, p. 27), "This condition precludes institutionalised value patterns that deny some people the status of full partners in interaction - whether by burdening them with excessive ascribed difference or by failing to acknowledge their distinctiveness". Social justice principles are appropriate in the case of the increase in the number of postdoctoral research fellowships, leading to increased commodification of academic work. Stephan, Franzoni and Scellato (2015) note that business values and behaviours are beginning to influence the conduct of academic research, resulting in models oriented towards value for money.

A social justice agenda for HE in democratic societies connects moral and ethical dimensions of leadership to the pedagogy of social justice, in the increasingly pluralistic context of higher education institutions (HEIs). Scholars note the need for multifaceted and responsive leadership practices (e.g., Berkovich, 20I4; Capper and Young, 20I4; Marshall, 2004; Shields, 20I4) which promote social inclusivity to address a wide array of inequalities. Social justice advocates for equal opportunities and prospects for marginalised members of society (Jean-Marie, Normore, and Brooks, 
2009; Szeto and Cheng, 2018; Theoharis, 2009). The review thus viewed the structural and cultural disparities within the traditional hierarchy of the organisation and practices of HEIs through a social justice lens.

\section{Method}

The primary aim of the review was to identify and analyse research findings and evaluate the major themes emerging with the aim of contributing to the PDRF literature. The research was framed within the emancipatory paradigm which values critique and transformation, restitution and emancipation (Guba and Lincoln, I994). Its key concepts are advocacy and activism centred on the lives and experiences of diverse groups that have traditionally been marginalised, focusing on how their lives are individually or collectively constrained. It seeks to critique and transform social, political, cultural, economic, and ethnic and gender structures that limit human justice and democracy and exploit people (Guba and Lincoln, I994).

The review adopted an inclusive approach, with empirical studies using qualitative, quantitative or mixed methods considered, as were conceptual / commentary and research reviews. This ensured a more representative sample of the PDRF literature.

\subsection{Research Approach and Data Collection}

The 45 publications were identified by means of systematic search criteria using search engines Google, Google Scholar, Research Gate, UJoogle and the SCOPUS database. The search criteria included: I) peer-reviewed English-language journal articles, 2) book chapters, 3) conference papers, 4) available full text, 5) published between 2005 and 2018 and 6) examined postdoctoral research fellowships. Checks of reference lists and hand searches of journals were employed as supplementary approaches to identify further publications. The full text of the identified studies was stored in a marked folder on a desktop computer. The studies were screened through examining topics and abstracts, and at this stage some were excluded because they did not meet the criteria. A total of 45 studies which met the eligibility criteria remained, and they formed the sample.

\subsection{Data Analysis}

The 45 documents were reviewed according to the research questions. Author name(s), year, topic, publication outlet, methodology, type of paper (empirical, conceptual/ commentary, review), the aims of the study, geographical location and major findings were captured on a Microsoft Excel spreadsheet. Of the 45 documents, I2 utilised a quantitative approach, seven a qualitative methodology, five used mixed methods, Io were reviews and ro were conceptual. Themes began to emerge during the research synthesis, and the individual themes were clustered to form a group of common main themes. This facilitated the organisation of the literature review (Peruzza and Kinsella, 2010).

\section{Findings}

Postdoctoral research fellows have obtained $\mathrm{PhD}$ degrees and are pursuing additional research training to develop skills in pursuit of an academic research or other career (Lee, 2013). They work under the mentorship of faculty or departmental members for a defined period of time. While the traditional understanding of PDRFs is that of PhDs in training for faculty careers, the changing political economy has reshaped their work from apprentices to temporary employees with some remaining PDRFs indefinitely (Cantwell and Lee, 20I0). As a result of an oversupply of PhDs, some move from one short-term funded project to another. Bodin et al. (20I8) note that the concept of PDRFs continues to evolve and is made up of several submarkets; entry level job, research fellowship, general fellowship and postdoctoral fellowship. The fact that PDRFs are now used as temporary employment results in exploitation (Akerlind, 2005).

\subsection{Purpose of Postdoctoral Research Fellowships} 4.1.1 Roles and Responsibilities of PDRFs

Six of the reviewed studies explored the roles, responsibilities, purpose and function of PDRFs. McQuaid and McCutcheon (20I8) and Silberbogen et al. (20I8) note that a postdoctoral research fellowship is different from an entry-level position or internship in that it involves mentored training that develops advanced competencies within a specific focus area. Akerlind (2005) observes that the growth of postdoctoral research fellowships at the international level has resulted in a lack of systematic definition of PDRF positions. This has led to casualisation and PDRFs being undervalued. The marginalisation of PDRFs violates the social justice principle of supporting and protecting vulnerable and disadvantaged groups (Pro Bono Resource Centre, 20II)

\subsubsection{Recruitment of PDRFs}

While Bodin et al. (2018) reviewed the recruitment and selection of PDRFS in Health Sciences Psychology in the US, their recommendations are applicable to any institution. They include the involvement of training councils, for instance, the Universal Psychological Postdoctoral Directory (UPPD) and larger national organisations to facilitate the appointment of PDRFs. Williams, Sayegh and Sherer's (20I8) empirical study concluded that postdoctoral research fellowships had the potential to develop scientist practitioners through developing the relevant knowledge, skills and attitudes. 


\subsubsection{Skills Development}

Postdoctoral research fellowships help incumbents to strengthen their research skills; build a collaborative research agenda; grow intellectually; pursue independent research; advance competency within a focus area; strengthen theoretical and methodological approaches; learn how to apply for research grants; and establish a research niche with manuscripts in different stages. In addition, the requirements of submitting manuscripts to peer-reviewed journals, having an identified mentor, and provision of structured support lead to higher publication rates and development of scholarly skills. Lembani et al.'s (20I6) empirical investigation of the usefulness of postdoctoral research fellowships concluded that they offer a range of learning experiences, including teaching and research, academic writing skills and community dialogue. The authors recommended that more institutions in Africa should adopt the system.

While the abovementioned studies were conducted in developed contexts, their findings could offer lessons for African institutions.

\subsection{Career Prospects}

Overall, eight studies found that PDRFs are required to develop advanced and specialist competencies (Blackford, 20Io; Self, Beauvais, Wise, and Molinari, 20I8; Stacy, Klee, and Jansen, 20I8; Yang and Webber, 2015). Almost all those that participated in these studies expressed the desire to remain in the academic field; however, they were uncertain of their future prospects, especially in the social sciences and humanities. This resulted in reduced job satisfaction (van der Weijden, Teelken, de Boer, and Drost, 20I6). Zubieta (2009) employed quantitative methods to study the effect of PDRFs' mobility on academic performance and established that undertaking a postdoctoral fellowship in another country positively influenced their publishing record, as weak institutions maintained ties with those with good reputations. Ghaffarzadegan, Hawley and Desai (20I4) analysed the diversification of the national and international research workforce and found that the US government supported PDRFs in biomedical sciences in order to develop a strong domestic research workforce. However, institutions are also taking advantage of vulnerable migrant PDRFs while making their name in global rankings.

The US has adopted policies that favour international PDRFs (Desai, 20I4). Stacy et al. (20I8) established that PDRFs gained confidence and refined the broad range of professional skills required at entry level. As the concept of postdoctoral research fellowships is evolving, its purpose in professional preparation is becoming more apparent (Self et al., 20I8). Yang and Webber's (20I5) analysis concluded that completion of such a fellowship makes a positive contribution in securing tenure-track appointments.
Renner and Ayers (20I4) used mixed methods to unveil the research and professional activities of PDRFs in small business, highlighting that they gained project management and team building skills, mentoring and positively impacting on companies through supporting the manufacturing sector. While most of these studies were conducted in the health sciences, they have critical implications for policy and practice in Africa, warranting further research.

\subsection{Benefits and Opportunities}

The literature shows that most PDRFs are involved in full time research, giving them ample time to publish (Renner and Ayers, 20I4; Self et al., 20I8; Zubieta, 2009). This time is also utilised to engage in research as a stepping stone towards a permanent position. As such, PDRFs gain independence and flexibility in research. They also have opportunities to apply for grants. Akerlind (2005) refers to a postdoctoral research fellowship as, "a unique research opportunity to concentrate on researching and writing for publication in a way impossible at late stages of a career".

The movement of PDRFs beyond national borders due to local deficits (push factors) and desirable conditions (pull factors) coincides with globalisation (Cantwell and Taylor, 20I3). Stephan, Franzoni and Scellato's (2015) survey of research scientists in I6 countries established that the major reason why the US is ranked the highest in research outputs is the prestige of its programmes and career prospects, as well as fringe benefits that attract not only PDRFs, but PhD students. Australia, Germany, Switzerland, France and Great Britain are also favoured (Stephan et al., 20I6). Lee, Gowers, Ellis and Bellantuonoa's (2010) empirical study reported increased research output as a result of mobility between institutions; these findings were used to develop a programme to address issues within the lower ranks. Streatfield, Allen and Wilson (2010) emphasised the need for research workshops to address inadequate resources. Akerlind (2009) used mixed methods to examine postdoctoral research fellowships as preparation for an academic career, while Davis (2005) showed that both PDRFs and mentors benefited from a structured plan stipulating their respective obligations.

Su's (2009) quantitative study found that postdoctoral research fellowships boosted individual research productivity, especially among PDRFs placed in highly prestigious departments. McQuaid et al. (2018) and Williams et al. (20I8) reported that such fellowships increased PDRFs' publication rate as well as that of their supervisors while contributing to the broader scientific community. Since these studies indicated that the success of PDRFs depends on good mentorship, a research review that provides an update on supervision would be timely. Furthermore, given 
that most studies have been conducted in the health sciences, empirical research in other disciplines is warranted especially in the humanities.

4.4 Financial Aid and Support

Ahmed, Plotkin, Bao-Li and Kawahara (20I5) used quantitative methods to compare funding of the sciences in the US and China. They confirmed that the former leads the way in terms of research production due to its long tradition of recruiting talented PRDFs from around the globe and offering attractive opportunities for PDRFs. Generous funding boosts the number of PDRFs and subsequently impacts on research productivity (Jacob and Lefgren, 20II). Robertson, Klingensmith and Coopersmith's (2007) empirical research employed a quantitative approach and established that PDRFs who dedicated research time during surgical residency obtained funding. Chen, McAlpine and Amundsen (20I5) and Dolan and Johnson (2009) concluded that with support, especially with regard to supervision, PDRFs can overcome constraints. However, intra- and inter-institutional mobility provides the context within which PDRFs frame their horizons. and there is a need to structure these positions in a manner that minimises economic and social inequalities. These findings raise the need for empirical research on the funding of PDRFs in Africa. Since most of the studies used a quantitative methodology, future research could apply mixed methods to obtain more in-depth data.

\subsection{Gender Issues}

Six studies examined gender issues and concluded that gender did not have a significant impact on PDRFs' research output (Bend and Ute, 20I2; Borrego, Barrios, Villarroya, and Olle, 20I0); rather, institutions should recognise that female PDRFs experience barriers that are universally shared by women in the workplace (Paravina et al., 2010). Bernd and Ute (2OI2) found that women PDRFs demonstrated superior incentives to conduct research and had more citations. Women with low institutional support and more family responsibilities were less satisfied with their jobs (Felisbrti and Sear, 20I4). Another study highlighted gender disparities in the work environment which might hinder PDRFs' career prospects and choices (Martinez et al., 2007). It would seem that gender issues have not been adequately examined; thus, future research should employ qualitative methods to explore female PDRFs' experiences. A research review could also assist in unveiling the dilemmas they confront in the workplace.

\subsection{Constraining Factors}

The majority of the studies in our database (I2) examined the challenges experienced by PDRFs. In terms of mobility and systemic factors and /or structural constraints, they point to inadequate support; invisibility; limited influence in the processes that shape their professional lives (Camacho and Rhoads, 20I5); the difficulty of transferring their knowledge upon completion of the fellowship (Melin, 2005); and different treatment and expectations, as well as cultural stereotypes (Black and Stephan, 20Io; Cantwell and Lee, 20I0). Exploitation of PDRFs from developing countries; social isolation; verbal insults; harassment and international PDRFs' inability to challenge exploitation were also cited (Lee, 20I3). Some institutions were not equipped to support the transition of PDRFs and nurture them to become faculty members (Ahmed et al., 20I5). Cantwell and Lee (20I0) described how unequal access to opportunities was maintained in what they called academic capitalism. Host institutions benefited from higher levels of knowledge production at very low cost as they paid stipends and offered no professional security (Lee et al., 20I0). Lembani et al. (20I6) also found that developing countries did not provide committed mentorship; hence PDRFs networked to find employment in developed countries.

Cantwell and Lee's (2010) study established that, due to economic constraints, universities were likely to rely on less expensive PDRF labour which is subsidised by external grants, instead of faculty positions. They add that reliance on contingent academic labour enabled exploitation of PDRFs from developing countries, leading to uneven expectations and experiences. Universities thus became business enterprises (Camacho and Rhoads, 20I5).

McAlpine and Amundsen (20I5) and Muller and Kenney (20I4) focused on structural and societal factors, including supervision, and found that many PDRFs were not valued by supervisors; refused funding for conferences; not supported to network, and were belittled for efforts to solve the problems. Furthermore, the supervisor role was not officially recognised and they were unable to develop their own research plan while working on supervisors' projects. Focusing on research is also problematic, as PDRFs lack teaching experience. Laudel and Glaser (2008) and Akerlind (2005) note that postdoctoral research fellowships run the risk of deskilling PDRFs because they are not exposed to other academic avenues and their supervisors control their activities. Furthermore, such fellowships are temporary positions, with stipends set lower than tenure-track faculty positions. Those that do not publish in peer-reviewed journals cannot secure tenure-track faculty positions (Mendoza et al., 2013).

Other impediments that prevent PDRFs from taking advantage of this opportunity include uncertainty about their supervisors' responsibilities, inhibiting discussion of career and research prospects (Akerlind, 2005). PDRFs are isolated, making it difficult to collaborate with faculty members other than supervisors. The situation is compounded by the lack of formal 
acknowledgement due to the absence of systematic institutional policies and structures for career support (Felisberti and Sear, 20I4). McAlpine and Amundsen (20I5) established that since PDRFs work under supervisors, this hierarchical structure enables abuse of power. Supervisors mentor as they see fit because their authority is final and not questioned; therefore, PDRFs' experiences depend on the good will of the supervisors; they also get no vacation or sick days, and have to work continuously, until late and during weekends (Camacho and Rhoads, 20I5). The academic environment allows a few star professors to determine the employment of PDRFs, leaving them as commodities to be managed (Camacho and Rhoads, 20I5). Camacho and Rhoads (20I5) add that international PDRFs do not question research projects out of fear of rocking the boat. All these challenges can be addressed through enacting social justice. Although the reviewed studies were conducted in health and science disciplines, rigorous research is required on best practices to overcome these challenges.

\section{Discussion}

The review revealed that, while PDRFs, mentors and universities benefit from postdoctoral fellowship programmes, the culture in which such programmes occur undermine social justice. Indeed, the system not only marginalises those that are socially, educationally, and professionally disadvantaged due to poverty, race, ethnicity, religion, language, culture, immigrant status or gender, but to a large extent, undermines the voices of those that are fighting for equality and social justice. Individuals, practitioners, scholars and programmes that lobby for the disruption of normative discourses, are often isolated and have limited resources to make their voices heard - hence, the dearth of PDRF literature and research in Africa.

The findings also showed that it is difficult to implement suitable policies and procedures in the absence of explicit acknowledgment of the varying nature of postdoctoral research fellowship positions. One-size-fits-all policies may not be suitable for different contexts. The recent expansion of PDRF ranks could be the result of economic and political factors (Davis, 2005) which have triggered structural changes in the labour market, whereby such fellowships have evolved from being optional to becoming a prerequisite for securing few and far between faculty positions. Felisberti and Sear (2OI4) point to fierce competition amongst researchers as universities have a large pool of would-be PDRFs to choose from, especially from less developed countries.

The review also revealed that PDRFs are prone to abuse when host countries and institutions focus on building a strong research workforce at minimal cost. Furthermore, the sole focus on research constricts their future job prospects. Postdoctoral research fellows depend on their supervi- sors for support and some supervisors do not provide financial support for conferences, editing and page fees, yet PDRFs' productivity is measured by publications. Host institutions benefit from international academic labour without providing professional security. The lack of structured systems to address these challenges is a social justice concern. Given that PDRFs are neither classified as students nor staff (Davis, 2005), they have no sense of belonging. Their meagre salaries in the form of stipends are far less than tenure-track faculty positions and many PDRFs have families. The low value placed on PDRFs results in unfavourable working conditions and they work constantly without taking leave. Forces of supply and demand determine their access to opportunities and PDRFs from abroad, especially developing countries, are treated differently from local citizens (Baral et al., 20I8).

Social justice may be adopted as a radical change process (MthethwaSommers, 20I4) that transforms traditional structures to achieve fairness for PDRFs. While there has been increased focus on social justice and education leadership (e.g., DeMatthews and Mawhinney, 2018; Jean-Marie et al., 2009; Shields, 20I4; Theoharis, 2009) since the turn of the $2 \mathrm{I}^{\text {st }}$ century, none of the studies paid attention to HE, as is evident in the silence on the issue in our sample of 45 studies. Social justice should be infused in all aspects of leadership in HE. University leaders must prepare for the complex new social order that comprises a variety of nationalities. While the review shed light on the marginalisation of social justice with regard to PDRFs, further research is required in several areas in order to propose a theory of social justice leadership. However, policies could be crafted to alleviate the current situation of workplace vulnerability; for instance, by proactively addressing the challenges confronted by PDRFs. The paucity of empirical research on the experiences of female PDRFs is also cause for concern.

Social injustice arises when people in society are economically and socially stratified. The experiences of PDRFs highlighted by the review challenged HE leadership to critically reflect on their leadership strategies and mind-set. University leaders must strive to create environments that offer opportunities to all and give everyone a voice (Jayavant, 20I6). Building PDRFs' capacity benefits everyone, including universities. Indeed, Jayavant (20I6) found that effective leadership for social justice and equity resulted in improved student outcomes.

\subsection{Limitations}

The first limitation is that the search process for this review was limited to peer-reviewed journal articles, conference papers and book chapters published in English. The omission of publications in other languages as well as unpublished documents such as dissertations could mean that the data- 
base was not fully representative of the literature on this issue. However, given that the review relied on systematic search criteria, the identified publications provided insight on the status quo of the PDRF research literature. The second limitation is that most of the reviewed studies were conducted in developed countries and they mainly focus on health and the sciences. The context may differ in developing societies as well as in the social sciences and humanities. Finally, although systematic search criteria were used to identify the studies, Hallinger (20I6) emphasises that no single method can be claimed to be Ioo\% effective. Thus, it is possible that some publications were left out. All these limitations could be addressed in future studies.

\subsection{Implications and Conclusion}

In conclusion, the six themes that emerged from the review, namely, the purpose of postdoctoral research fellowships; career prospects; benefits and opportunities; financial aid and support; gender issues and constraining factors, highlighted the social inequalities associated with the PDRF position. In addressing these issues, university leadership should strive to promote equality and equity among diverse students (Szeto and Cheng, 20I8), in this case PDRFs. There is an interplay between university leadership's values in relation to social justice and the effects of the diversity of PDRFs which are intertwined with traditional university mechanisms and the hierarchy of practices (Szeto and Cheng, 2018). These emanate from the structure of the system and deep-rooted perceptions, beliefs and norms. The social justice issues emphasised in relation to contextual changes, practices and procedures ingrained in individual universities, further complicate efforts to achieve equality and equity.

The literature attests to neglect of equity issues in educational leadership (Capper and Young, 20I4; DeMatthews and Mawhinney, 2018; Jean-Marie et al., 2009; Shields, 20I4; Szeto and Cheng, 2018; Theoharis, 2009) and debate on how such leadership can promote social justice is gaining momentum (Capper, Theoharis and Sebastian, 2006; Jean-Marie et al., 2009; Szeto and Cheng, 20I8; Parker et al., 2005; Tillman, Brown, Campbell-Brown, and Gonzalez, 2006; Theoharis, 2009). University leadership is thus called on to disrupt and subvert arrangements that sustain marginalisation and exclusion. It should also be acknowledged that preparing leaders for social justice is a complex and multidimensional task and cannot be confined to a list of 'to do' items.

Higher Education Institutions need to create broader training and opportunities to develop skills that enhance the marketability of PDRFs and also offer career counselling. Indeed, the PDRF programme can be utilised as a powerful resource for development. Review of PDRF training pro- vides deeper insights and guides theory and practice in areas that require improvement. Given the shortage of faculty positions, research is required on the trends associated with acquiring faculty jobs. In addition, further research is warranted to investigate changing patterns in research work as well as PDRFs' contribution to knowledge production. Changing patterns in research impact PDRFs differently. For instance, migrant PDRFs from developing countries may be vulnerable to exploitation (Cantwell and Lee, 2010; Whitworth et al., 2008). The experiences of long-term PDRFs who have migrated from one institution to another need to be examined to gain an understanding of new patterns of academic labour among different groups.

Given that forced mobility is on the increase, the relationship between identity and academic work cannot be ignored. Pratt-Clarke (20I0) warns that subtle acts of oppression, domination and institutionalised practices are often taken for granted as norms, rules, and values because their seeming 'natural' status has remained unchallenged. Therefore, further research should explore the intersection between race, gender and nationality and academic career opportunities in academia. The review highlighted the importance of interrogating how academic job opportunities are sustained by academic capitalism, power hierarchies and globalisation. While employment opportunities have been created for PDRFs, especially those from developing regions, Cantwell and Lee (20I0) assert that these are potentially exploitative and are hindering career progression. Host countries continue to benefit from the influx of academics from abroad. Hence, future research should critically examine how academic capitalism creates unequal patterns of opportunities. Since universities are becoming business enterprises, they must protect and support their resources, including PDRFs, not only the few star professors who command high salaries and benefits. Postdoctoral research fellows should be paid reasonable salaries and have access to benefits such as annual and parental leave (Camacho and Rhoads, 20I5). Universities also need to establish support structures, especially for international PDRFs, and grievance procedures (Whitworth et al., 2008). Finally, innovative leadership strategies need to be crafted to address social justice issues within specific contexts. African universities cannot solve their problems by borrowing directly from developed settings, but need to come up with solutions that are grounded in their social, economic, cultural and political contexts.

\section{References}

Ahmed, A. Z., Plotkin D., Bao-Li, Q., and Kawahara, A. Y. (20I5). Postdocs in science: a comparison between China and the United States. BioScience 65(II), I088-I095. 
Akerlind, G. S. (2005). Postdoctoral researchers: roles, functions and career prospects. Higher Education Research and Development 24(I), 2I-4O.

Akerlind, G. S. (2009). Postdoctoral research positions as preparation for an academic career. International Journal for Researcher Development 1 , 84-96.

Berkovich, I. (20I4). A socio-ecological framework of social justice leadership in education. Journal of Educational Administration 52(3), 282-309.

Bernd, F., and Ute, L. (20I2). Up or out: Research incentives and career prospects of postdocs in Germany, ZEW Discussion Paper No. I2-020. Zentrum für Europäische Wirtschaftsforschung (ZEW), Mannheim.

Black, G. C., and Stephan, P. E. (20I0). The economics of university science and the role of foreign graduate students and postdoctoral scholars. In C. T. Clotfelter (ed.), American Universities in a Global Market (pp. I29-I6I). University of Chicago Press.

Blackford, S. (2010). A qualitative study of the relationship of personality type with career management and career choice preference in a group of bioscience postgraduate students and postdoctoral researchers, International Journal for Researcher Development 1(4), 296-313.

Bodin, D., Lemle, R. B., Goldberg, R. W., Perry-Parrish, C., Kuemmel, A., Schmidt, J. P., Hill, K. R., Williams, S. E., and Siegel, W. (20I8). Recruitment and selection in Health Service Psychology postdoctoral training: A review of the history and current issues. Training and Education in Professional Psychology 12(2), 74-8I.

Borrego, A., Barrios, M., Villarroya, A., and Olle, C. (2010). Scientific output and impact of postdoctoral scientists: a gender perspective, Scientometrics 83, 93-IOI.

Camacho, S., and Rhoads, R.A. (20I5). Breaking the silence: The unionization of postdoctoral workers at the University of California. The Journal of Higher Education 86(2), 29I-325.

Cantwell, B., and Lee, J. J. (2010). Unseen workers in the academic factory: Perceptions of neoracism among internal postdocs in the United States and the United Kingdom. Harvard Educational Review 80(4), 490-586.

Cantwell, B., and Taylor, B. J. (2013). Internationalization of the postdoctorate in the United States: Analysing the demand for international postdoc labour. Higher Education 66, 55I-567.

Capper, C. A., and Young, M. D. (20I4). Ironies and limitations of educational leadership for social justice: A call to social justice educators. Theory Into Practice 53, I58-164.

Capper, C. A., Theoharis, G., and Sebastian, J. (2006). Toward a framework for preparing leaders for social justice. Journal of Educational Administration 44(3), 209-224.
Chen, S., McAlpine, L., and Amundsen, C. (20I5). Postdoctoral positions as preparation for desired careers: a narrative approach to understanding postdoctoral experience. Higher Education Research and Development 34(6), 1083-1096.

Chiu, M. M., and Walker, A. (2007). Leadership for social justice in Hong Kong schools: Addressing mechanisms of inequality. Journal of Educational Administration 45(6), 724-739.

Davis, G. (2005). Improving the postdoctoral experience: An empirical approach. In R, Freeman and D. Goroff (eds), Science and engineering careers in the United States: an analysis of markets and employment (pp. 99-I27). University of Chicago Press.

DeMatthews, D., and Mawhinney, H. (20I4). Social justice leadership and inclusion: Exploring challenges in an urban district struggling to address inequalities. Educational Administration Quarterly 50(5), 84488I.

Devine, D. (2013). Practising leadership in newly multi-ethnic schools: Tensions in the field? British Journal of Sociology of Education 34(3), 392-4II.

Dolan, E., and Johnson, D. (2009). Toward a holistic view of undergraduate research experiences: an explanatory study of impact of graduate postdoctoral mentors. Journal of Science Education and Technology 18(6), 487-500.

Felisberti, F. M., and Sear, R. (20I4). Postdoctoral researchers in the UK: A snapshot at factors affecting their research output. PLoS One 9(4), e93890.

Fraser, N. (2007). Feminist politics in the age of recognition: A two dimensional approach to gender justice. Studies in Social Justice 1(I), 23-36.

Ghaffarzadegan, N., Hawley, J., and Desai, A. (20I4). Research workforce diversity: the case of balancing national versus international postdocs in US biomedical research. Systems Research and Behavioural Science 31(2), 3OI-3I5.

Goran, M. (2005). International experience. The dark side of mobility: negative experiences of doing a postdoc period abroad. Research Evaluation 14(3), 229-237.

Guba, E. G., and Lincoln, Y. S. (I994). Competing paradigms in qualitative research. Handbook of qualitative research 2(163), I94-105.

Hallinger, P. (2016). Bringing context out of the shadows of leadership. Educational Management Administration and Leadership 46(I), 5-24.

Jacob, B. A., and Lefgren, L. (2OII). The impact of NIH postdoctoral training grants on scientific productivity. Research Policy 40(6), 864-874.

Jayavant, S. (2016). Mapping the complexities of effective leadership for social justice praxis in urban Auckland primary schools. Educ Sci. 6(I), II. https://doi: Io.3390/educsci6orooII 
Jean-Marie, G., Normore, A. H., and Brooks, J. S. (2009). Leadership for social justice: Preparing $2 \mathrm{I}^{\text {st }}$ century school leaders for a new social order. Journal of Research on Leadership Education 4(I), I-3I.

Laudel, G., and Glaser, J. (2008). From apprentice to colleague: The metamorphosis of early career researchers. Higher Education 55, 387-406.

Lee, J. J. (2013). The false halo of internationalization. International Higher Education 72, 5-7.

Lee, L. J., Gowers, I., Ellis, L., and Bellantuonoa, I. (2010). Well-rounded Postdoctoral Researchers with initiative, who are not always "tied to the bench" are more successful academically. International Journal for Researcher Development 1(4), 269-295.

Lembani, M., Teddy, G., Molosiwa, D., and Hwabamungu, B. (20I6). Postdoctoral research fellowship as a health policy and systems research capacity development intervention: a case of the CHESAI initiative. Health Research Policy and Systems 14(89), I-I3.

Marshall, C. (2004). Social justice challenges to educational administration: Introduction to a special issue. Educational Administration Quarterly 4O(I), 3-I3.

Martinez, E. D., Botos, J., Dohoney, K. M., Geiman, T. M., Kolla, S. S., Olivera, A., Qiu, Y., Vani Rayasam, G., Stavreva, D. A., and Cohen, O. (2007). Falling off the academic bandwagon. Women are more likely to quit at the postdoc to principal investigator transition. EMBO Rep 8(II), 977-981.

McAlpine, L., and Amundsen, C. (20I5). Early career researcher challenges: substantive and methods-based insights. Studies in Continuing Education 37(I), I-I7.

McKenzie, K. B., Christian, D. E., Hernandez, F., Fierro. E., Capper, C. A., Dantley, M., Gonzalez, M. L., Cambron-McCabe, N., and Scheurich, J. J. (2007). From the field: A proposal for educating leaders for social justice. Educational Administration Quarterly 44(I), III-I38.

McQuaid, E. L., and McCutcheon, S. R. (20I8). Postdoctoral training in Health Service Psychology: introduction to the special section. Training and Education in Professional Psychology 12(2), 63-65.

McQuaid, E. L., Aosved, A. C., and Belanger, H. G. (2018). Integrating research into postdoctoral training in health service psychology: Challenges and opportunities. Training and Education in Professional Psychology 12(2), 82-89.

Melin, G. (2005). The dark side of mobility: negative experiences of doing a postdoc period abroad. Research Evaluation 14(3), 229-237.

Mendoza, N. S., Resko, S. M., DeLuca, S. M., Mendenhal, A. N. 1., and Early, T. J. (20I3). Social work and postdoctoral experience. Social Work Research 37(I), 76-80.
Moyo, Z., and Perumal, J. (20I8). Globalisation and the experience of Zimbabwean female migrant teachers. Journal of Educational Studies 17(I), 76-93.

Mthethwa-Sommers, S. (20I4). What is social justice education? In S. Mthethwa-Sommers (ed.), Narratives of Social Justice Educators (pp. 7-25). Springer, Cham.

Muller, R., and Kenney, M. (20I4). Agential conversations: Interviewing postdoctoral life scientists and the politics of mundane research practices. Science as Culture 23(4), 537-559.

North, C. E. (2006). More than words? Delving into the substantive meaning(s) of "social justice" in education. Review of Educational Research 76, 507-535.

Paravina, R. D., O'Neill, P. N., Swift, E. J., Nathan, D., and Goodcare, C. J. (20IO). Teaching of colour in predoctoral dental and postdoctoral dental education in 2009. Journal of Dentistry 38(2), e34-e40.

Peruzza, N., and Kinsella, E. A. (2010). Creative arts occupations in therapeutic practice: a review of the literature. British Journal of Occupational Therapy 73(6), 26I-268.

Pratt-Clarke, M. A. E. (2010). Critical race, feminism and education: A social model. New York: Palgrave Macmillan.

Pro Bono Resource Centre. (20II). Occasional paper Number 1. What is social justice? Australia, University of South Wales.

Renner, J. N., and Ayers, K. E. (20I4). Exploring electrochemical technology: A perspective on the ASEE/NSF small business postdoctoral research diversity fellowship. Proceedings of 20I4 Zone I Conference of the American Society for Engineering Education (pp. I-5).

Robertson, C. M., Klingensmith, M. E., and Coopersmith, C. M. (2007). Long-term outcomes of performing a postdoctoral research fellowship during general surgery residency. Annals of Surgery 245(4), 516-523.

Self, M. M., Beauvais, J., Wise, E. H., and Molinari, V. (2018). Ethics in training and training in ethics: special considerations for postdoctoral fellowships in Health Service Psychology. Training and Education in Professional Psychology 12(2), IO5-II2.

Shields, C. M. (20I4). Leadership for social justice education: a critical transformative approach. In I. Bogotch and C.M. Shields (eds), International handbook of educational leadership and social (in) justice (pp. 323-340). London: Springer.

Silberbogen, A., Aosved, A. C., Cross, W. F., Cox, D. R., and Felleman, B. I. (20I8). Postdoctoral training in health service psychology: Current perspectives in an evolving profession. Training and Educational Professional Psychology 12(2), 66-73.

Stacy, M., Klee, A., and Jansen, M. (2018). Postdoctoral psychology train- 
ing in preparation for specialization in serious mental illness. Training and Education in Professional Psychology 12(2), 96-104.

Streatfield, D., Allen, D., and Wilson, T. (2010). Information literacy training for postgraduate and postdoctoral researchers: a national survey and its implications. Libri 60, 230-240.

Stephan, P., Franzoni, C., and Scellato, G. (20I5). Global competition for scientific talent: Evidence from location decisions of PhDs and postdocs in 16 countries. Industrial and Corporate Change 25(3), 457-485.

$\mathrm{Su}, \mathrm{X}$. (2009). Postdoctoral training, departmental prestige and scientists' research productivity. Journal of Technology Transfer 36, 275-29I.

Szeto, E., and Cheng, A. Y. N. (20I8). How do principals practise leadership for social justice in diverse school settings? A Hong Kong study. Journal of Educational Administration 56(I), 50-68.

Theoharis, G. (2009). The school leaders our children deserve: Seven keys to equity, social justice, and school reform. New York, NY: Teachers College Press.

Tillman, L., Brown, K., Campbell-Jones, F., and Gonzalez, M. L. (2006). Transformative teaching for social justice in educational leadership. Journal of School Leadership 16(2), 207-209.

Van der Weijden, I., Teelken, C., de Boer, M., and Drost, M. (2016). Career satisfaction of postdoctoral researchers in relation to their expectations for the future. Higher Education 72, 25-40.

Whitworth, J. A. G., Kokwaro, G., Kinyanjui, S., Snewin, V. A., Tanner, M., Walport, M., and Sewankambo, N. (2008). Strengthening capacity for health research in Africa. Lancet 372(9649), I590-I593.

Williams, M. E., Sayegh, C. S., and Sherer, S. (20I8). Promoting scholarly training in a clinical psychology postdoctoral fellowship. Training and Education in Professional Psychology 12(2), 90-95.

Yang, L., and Webber, K. L. (20I5). A decade beyond the doctorate: the influence of a US postdoctoral appointment on faculty career, productivity, and salary. Higher Education 70, 667-687.

Zubieta, A. F. (2009). Recognition and weak ties: Is there a positive effect of postdoctoral position on academic performance and career development. Research Evaluation 18(2), I05-II5. 